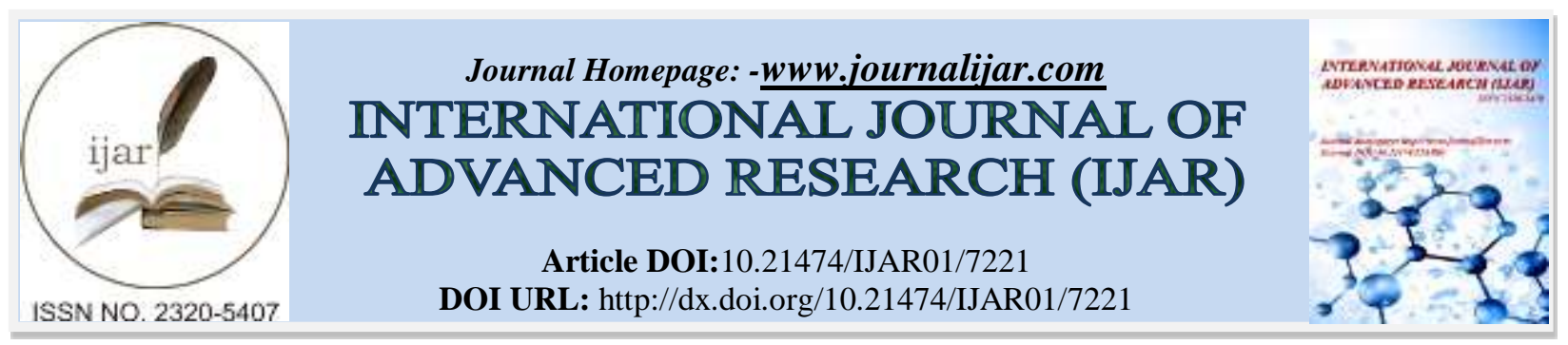

RESEARCH ARTICLE

\title{
A PROSPECTIVE STUDY OF FUNCTIONAL OUTCOME IN TREATMENT OF FRACTURE OF RADIUS AND ULNA WITH LOCKING COMPRESSION PLATE.
}

\author{
Mohit Mehmi, Ramesh Chand Jindal, Jatin Aggarwal,Naman Tuteja, Anil Kumar Chaudhary, Aryan \\ Sharma, Vineet Pruthi and Rajdeep Singh Bajwa.
}

\section{Manuscript Info}

Manuscript History

Received: 06 April 2018

Final Accepted: 08 May 2018

Published: June 2018

\section{Abstract}

Copy Right, IJAR, 2018,. All rights reserved.

\section{Introduction:-}

The human forearm plays a very important role in upper extremity function, enabling placement of the hand in space, thereby providing the upper extremity with its unique mobility. Mal-union and non-union occurs more often because there is difficulty in reducing and maintaining the reduction in the presence of pronating and supinating muscles that have angulating and as well as rotational influences. Because of these factors, ORIF for diaphyseal fracture in the adults were generally taken as the best method of treatment, even though closed reduction might be achieved. ${ }^{\mathrm{i}}$

Anderson had reported a union rate of $97.3 \%$ in cases of fractures treated with open reduction and internal fixation (ORIF) using compression plates. ${ }^{\text {ii }}$ Of these patients, $90 \%$ had satisfactory or excellent function, and only $10 \%$ had unsatisfactory or poor function. Sage reported a union rate of $93.8 \%$ for fractures treated with triangular nails. ${ }^{\text {iii }}$ The important feature common to these studies, in which a union rate of more than $90 \%$ was reported, was the rigidity of the fixation. If intramedullary nails were used, they must control rotation of the fragments and be sturdy enough to resist angulatory forces. If plates and screws were used, the same must have been long enough and strong enough to resist loosening and breakage.

A clear understanding of bone biology and the roles tissue vascularity and gap strain played in fracture healing, contributed greatly to the development of the concept of bridging plate osteosynthesis and the use of locked plate technology. ${ }^{\text {iv }}$ The Schuhli-Nut, Pc-Fix, and Zespol plates were early attempts at creating an internal fixator. ${ }^{\mathrm{v}}$ By firmly fixing the screw to the plate, the plate screw construct could act as a fixed-angle device, with the screws functioning as threaded locked bolts. vivii Devoid of the need to apply the plates directly to the bony surface, the locked plate created a more biologic approach to the management of fractures, allowing for indirect reduction using minimally invasive percutaneous plating techniques. The aim of this study was to assess the functional outcome of treatment of fractures of forearm bones by internal fixation with locking compression plate and to observe and manage the complications. 


\section{Material And Methods:-}

The proposed study was conducted in tertiary care centre that included 30 patients suffering from fracture in the forearm bones reporting to the hospital in emergency and outpatient department. The inclusion criteria was Fracture both bones of forearm in metaphyseal and diaphyseal region. Closed and grade 1 compound forearm fracture were also included in this study.

Associated nerve and vessel injury ,compartment syndrome, floating elbow, fractures in children, type 2 and type 3 compond fractures and pathological fractures were excluded from this study.

\section{Study Tool:-}

1. Fractures were classified as according to the AO Classification

2. Grading the functional outcome according to Anderson criteria

\section{Procedure and methodology:-}

On admission of patient, a thorough clinical examination was made including systemic examination to rule out any associated any injury. Antero-posterior and lateral radiographs of affected forearm including elbow \& wrist joint were done. The radius was exposed through the Anterior Henry approach and the plate applied to volar surface, when the fracture was on the lower two-third or through the dorsal Thompson approach and the plate placed on the dorsal plate when the fracture was on upper third. The ulna was exposed through the postero - medial subcutaneous surface and the plate was applied on the posterior surface since it was the tension side of ulna. Radius was fixed first followed by ulna. Fractures were classified as according to the AO Classification into type A (extra-articular), type B (partial articular) and type C (complete articular).

\section{Preoperative Evaluation:-}

A written and informed consent was taken. Appropriate length of the plate to be used was assessed with help of radiographs. A dose of IV antibiotic was given 1 hour before the start of surgery

\section{Post operation evaluation:-}

Antibiotics \& analgesics continued for 5 days.Suture removal done after 10 days. Depending on the degree of commination slab was discarded after Suture removal at 3 wks. Active elbow, wrist \& finger movements encouraged.The patient were called for check-up first on 14th post- operative day and then on completion of 4 weeks and later after every 2 weeks. The patients were followed up clinicoradiologically for a minimum period of 6 months. Initially the patients were evaluated every 3-4 week intervals till the fractures union, every 6 weeks thereafter for 3 months and then at 3 monthly intervals. The results were evaluated on the basis of fracture union, range of movements, muscle (grip) strength and complications.

Criteria for functional results The Criteria of Anderson et alError! Bookmark not defined. were used in grading the functional outcome, which is as follows (table A)

\begin{tabular}{|l|l|l|l|}
\hline Results & Union & $\begin{array}{l}\text { Flexion and extension at } \\
\text { Elbow joint }\end{array}$ & $\begin{array}{l}\text { Supination and } \\
\text { pronation }\end{array}$ \\
\hline Excellent & Present & $<10^{0}$ Loss & $<25 \%$ loss \\
\hline Satisfactory & Present & $<20^{0}$ loss & $<50 \%$ loss \\
\hline Unsatisfactory & Present & $>20^{0}$ loss & $>50 \%$ loss \\
\hline Failure & Non - union or unresolved chronic osteomyelitis \\
\hline
\end{tabular}

The patient rated outcome was assessed using the Disabilities of the Arm, Shoulder and Hand (DASH) questionnaire, a 30-item questionnaire intended to assess the function and symptoms of patients with disorders of the upper limb.

\section{Statistical analysis:-}

Statistical analysis was made using the software SPSS 23. Data was represented by Mean \pm SD and frequency (percentage). Difference was considered significant when the $\mathrm{p}$ value was $<0.05$.

\section{Results And Observation:-}

The below table shows the demographic data of male and female patients ,time taken for union, functional outcome as per anderson's criteria and complications associated with LCP. 


\begin{tabular}{|l|l|l|}
\hline & Number of patients(N) & Percentage(\%) \\
\hline Gender & & \\
Male & 20 & $66.7 \%$ \\
Female & 10 & $33.3 \%$ \\
\hline Time taken for union & & \\
<16 weeks & 21 & $70 \%$ \\
$16-24$ weeks & 9 & $30 \%$ \\
Union of fractures & 30 & $100 \%$ \\
\hline Functional outcome(Anderson's criteria) & & \\
Excellent & 27 & $90 \%$ \\
Satisfactory & 3 & $10 \%$ \\
Unsatisfied & 0 & $0 \%$ \\
\hline Complications & & \\
Absent & 26 & $86.67 \%$ \\
Present & 4 & $13.33 \%$ \\
Stiffness & 2 & $6.67 \%$ \\
Superficial infection & 1 & $3.33 \%$ \\
Delayed union & 1 & $3.33 \%$ \\
\hline
\end{tabular}

The dash questionnaire for outcome was found to be $15.8(0-23.71)$

\section{Discussion:-}

The Locking Compression Plate system (LCP System) is a new type of extramedullary implant system for treating fractures. This system combines the facilities of conventional plate osteosynthesis with those of the internal fixator systems. In order to achieve this combination, a new style plate hole had to be designed. This new plate whole design permits the use both of standard screws and locking head screws (LHS), which achieve fixed-angle stability. ${ }^{\text {viii }}$

But reports on the results of clinical application of LCP are few, especially on its efficacy, or superiority over other plates in the treatment of diaphyseal fractures of forearm bones. This implant system offers the surgeon a variety of possibilities for treating fractures. The fact that many popular plate types have already been modified in accordance with this principle means that the surgeon can use the LCP for a great variety of indications and fracture patterns.

Locked plates the "internal external fixators", does not rely on frictional force between the plate and the bone to achieve compression and provide absolute stability. Thus, the local blood supply under the plate to be preserved, ${ }^{\text {ix }}$ thereby leading to superior bone healing and minimal complications. It has been proved to be valuable in situations like osteoporosis, comminuted fractures, complex intraarticulaar fractures or fractures in close proximity to the joints, upper extremity fractures. ${ }^{\mathrm{x}, \mathrm{xi} \text {,xii }}$ Atsunori et al. had stated that LCP is now considered to be superior to the conventional plating system in the treatment of forearm fractures. ${ }^{\text {xiii }}$

In non-anatomical reduced fractures, reduction plate was applied in a bridging mode, or a conventional mode without compression, or where small comminuted fragments are not precisely adapted for fear of avascularity. Since callus formation was found to be more in the non-anatomically reduced forearms, we agree with Leung $F$ that it is the quality of reduction and control of stability in LCP which determine the type and speed of healing. It also supports Wagner's view that the locked internal fixator technique allows but does not require precise reduction and that it gives priority to biology over mechanics. ${ }^{\text {xiv }}$ In the present study, the majority of patients fall under none (33.3\%) category followed by moderate amount (30.0\%) and in abundant amount $(23.3 \%)$ and minimum formation of callus is in $4(13.3 \%)$ patients according to amount of callus formation.

Meena RK et al reported in LCP group, there was abundant callus formation in 4 cases (20\%), moderate in 6 ( $30 \%)$, minimum in 3 cases $(15 \%)$ and no callus formation in $7(35 \%)$ which is similar to present study. Thus, callus formation was seen in sixty five percent in LCP group. Saikia et al reported that $56 \%$ of forearm in the LCP group healed with radiological evidence of callus formation of which, $17 \%$ showed abundant callus formation, $22 \%$ showed moderate callus formation, $17 \%$ showed minimal callus and the rest $44 \%$ had no callus formation. 
We observed the functional outcome according to Anderson's criteria and the majority of patients has excellent $(90.0 \%)$ outcome followed by satisfactory $(10.0 \%)$ outcome and unsatisfied outcome $(0.0 \%)$. In the study of Ranganath HD et al assessed the functional outcome according to Anderson scoring system which included evaluation of the movements and the radiological union. They found out that there was $86.6 \%$ patients with excellent results, $6.7 \%$ with satisfactory results, $6.7 \%$ with unsatisfactory and 0 with poor results which is similar to present study. Meena RK et al reported excellent functional outcome result in 18 patient (90\%), satisfactory in 2 patients (10\%) in LCP group.

The limitation of this study is small sample size study from a single center hence significant conclusions could not be drawn. LCP is an effective treatment option for fractures of both bones of forearm. The outcome is determined by using proper principles of plating. The present study could not prove LCP superiority because we did not compare other technique. It is the proper application of the principles of plating and not the type of plate which decides the outcome. Further long-term multicentric study is required to prove behaviours of the implant.

In conclusion, open reduction and internal fixation with LCP with strict adherence to surgical technique is the gold standard method of treatment in both bones forearm fractures with excellent results than other methods of treatment.

\section{References:-}

1. Crenshaw AH, Canale ST, Beaty JH, Editors. Campbell's operative orthopaedics Vol III. 11th Ed. Philadelphia: Mosby Elseviar; 2008. p . 3425-27

2. Anderson LD. Fractures. In: Crenshaw AH, ed. Campbell's Operative Orthopaedics. 5th ed. Vol 1. St Louis, Mo: Mosby; 1971:477-691.

3. Mackenney PJ, McQueen MM, Elton R. Prediction of instability in distal radial fractures. J Bone Joint Surg Am. 2006 Sep. 88(9):1944-51.

4. Perren SM. Evolution and rationale of locked internal fixator technology. Introductory remarks. Injury. 2001;32(Suppl 2):B3-9

5. Kolodziej P, Lee FS, Patel A, et al. Biomechanical evaluation of the

6. schuhli nut. Clin Orthop Relat Res. 1998;347:79-85.

7. Haidukewych GJ. Innovations in locking plate technology. J Am Acad Orthop Surg. 2004;12:205-212.

8. Perren SM. Evolution of the internal fixation of long bone fractures. The scientific basis of biological internal fixation: choosing a new balance between stability and biology. J Bone Joint Surg Br 2002;84:1093-1110.

9. Frigg R. Locking Compression Plate (LCP). An osteosynthesis plate based on the Dynamic Compression Plate and the Point Contact Fixator (PC-Fix). Injury. 2001;32(suppl2):63-66.

10. Egol KA, Kubiak EN, Fulkerson E, Kummer FJ, Koval KJ. Biomechanics of locked screws and screws. J Orthop Trauma. 2004;18:488-3.

11. Sommer C, Gautier E, Müller M, Helfet DL, Wagner M. First Clinical results of the locking compression plate. Injury. 2003;34:B43-54

12. Ling HT, Kwan MK, Chua YP, Deepak AS, Ahmad TS. Locking compression plate: A treatment option for diaphyseal nonunion of radius or ulna. Med J Malaysia. 2006;61:8-12.

13. Larson AN, Rizzo M. Locking Plate Technology and its application in upper extremity fracture care. Hand Clin. 2007;23:269-78.

14. Atsunori S, Genzaburo N, Tsukasa I, Naoya T. Treatment of forearm fractures using locking compression plate (LCP, AO/ASIF) Orthop Surg Traumatol. 2004;47:1293-8.

15. Wagner M. The general principles for the clinical use of LCP. Injury. 2003;34:B31-42. 